\title{
Analysis for Individual-authorization of Functional Food Materials in Korea
}

\author{
Chang-Gue Son \\ Liver and Immunology Research Center, Oriental Medical College in Daejeon University
}

\begin{abstract}
Objectives: This study aimed to provide basic information for the trend of individual-authorization on functional food materials in Korea to side of Korean medicine.

Methods: Approval of materials for individual-authorized functional food in Korea was analyzed from 2004 to August 2015 using database from Ministry of Food and Drug Safety (MFDS), regarding the kinds of function, materials and their functional level by year.

Results: Korean functional food market has rapidly grown to 1.56 trillion Won in 2014 , with about $10 \%$ of annual growth rate. In particular, the increase of individual-authorized functional food is worth of notices, in detail 313 kinds of functional materials covering 31 body functions have been approved by August 2015. $15.7 \%$ of individual-authorized functional foods have used the herbal materials. This quantitative and qualitative expansion of functional foods, especially of individual-authorized functional foods, will affect the herbal drug industry negatively. Conclusion: This study figured out the current pattern of material approval for individual-authorized functional food in Korea, which would be essential in development of strategies by Korean medicine community in order to overcome such conditions.
\end{abstract}

$\overline{\text { Key Words }}$ : Korean medicine, Functional food, Herbal drug

\section{Introduction}

The concept of functional food had been defined as nourishments that play roles of maintaining healthy status or reducing the disease-risk in 1980s in Japan $^{1)}$. According to the progression of aged society, prevalence of adult diseases and emphasis on preventive medicine, foods has been considered as important resources of remedies ${ }^{2)}$. The global functional food market is expected to reach 130 trillion dollars in 2015, from 89 trillion dollars in $2011^{3)}$. In Korea, the functional market size has increased about $10 \%$ annually, from 680 billion Won in 2005 to 1.56 trillion Won in 2014, which corresponds to $0.11 \%$ of Korean gross domestic product (GDP) in 2014 comparing to $0.07 \%$ in 2005 4).

Among functional foods, the individual-authorized functional food is particularly worth of notice in aspects of their functional position that is similar to herbal drugs ${ }^{5}$. The number of approved materials for the individual-authorized functional food has increased to 313 kinds in 2015 from 50 in 2008, and then many of them were originated from herbal plants ${ }^{6}$. The sum of individual-authorized functional foods was rapidly increased to 232 billion Won in 2013

\footnotetext{
- Received : 25 October 2015

- Revised : 28 December 2015

- Accepted : 29 December 2015

- Correspondence to: Chang-Gue Son

Liver and Immunology Research Center, Daejeon Oriental Hospital of Daejeon University,

22-5 Daehung-dong, Jung-gu, Daejeon, 301-724, Republic of Korea.

Tel : +82-42-229-6807, Fax : +82-42-257-6398, E-mail : ckson@dju.ac.kr
} 
compared to 42 billion Won in 2008 in Korea ${ }^{7)}$. On the contrary to this, the sum of herbal drug prescription covered by national health insurance is continuously decreasing, by 28 billion Won in $2013^{8}$. The official demands for individual-authorized functional foods are the scientific data for quality control and minimal clinical evidence, and moreover Korean government strongly supports the development of functional food industry ${ }^{9}$.

Facts mentioned above raise a concern that consumers may accept individual-authorized functional foods as alternatives of herbal drugs in Korea. This study was aimed to analyze the trend of individual -authorization of functional food materials in Korea, which is essential for Korean medicine to counteract.

\section{Methods}

\section{Study design}

In order to produce the impact pattern of individual -authorized functional food in Korea, the approved list of functions, materials and functional levels of them were analyzed by year.

\section{Data collection and analysis}

From electric database for functional food (http://www.foodnara.go.kr/hfoodi/) developed by Ministry of Food and Drug Safety (MFDS), the approved materials for individual-authorized functional foods were collected, using data from 2004 to August 2015. In addition, further data for functional foods were collected from the websites of Korea Food Research Institute (http://kfri.re.kr) and Korea Health Industry Development Institute (www.khidi.or.kr) respectively. These searches were performed using combinations of the following keywords: "food", "functional food", "individual-authorized functional food" respectively.

\section{Results}

\section{Definition of individual-authorized functional food}

In order to encourage the industry of functional food, "Functional Food Act" was separately introduced from "Food Sanitation Act" by Korean government in 2002, and then its enforcement regulation had been proclaimed in $2004^{10)}$. Comparing to $1^{\text {st }}$ nutritional function and $2^{\text {nd }}$ taste function in food, functional food emphasizes the $3^{\text {rd }}$ function of food, body modulation functions, which are classified into "function of disease-risk reduction" or 3 levels of "physiological function activity"11). Korean MFDS defines the functional food as the food products that are made of functional materials or compounds. There are two kinds of functional food, according to the used materials; one is food products made of "announced functional materials" available for anyone while other is "individual-authorized functional food" permitted to only initial developer using novelty approved materials ${ }^{12)}$.

\section{Physiological functions covered by individual-authorized functional food}

Korean MFDS had expanded the list of physiological functions covered by functional foods up to 31 kinds of functions in 2015 (Table 1). The physiological functions mainly included blood pressure control, cholesterol control, and body fat reducing function in 2004, and then its list expended including andropause heath control, premenstrual syndrome control, vaginal health control using lactic acid bacteria, and helping child growth. If any food materials has been authorized and used in other countries such USA or Japan, the physiological function and functional materials could be approved by Korean $\mathrm{MFDS}^{13)}$. The functional profile of functional foods will be further increased continuously depending on the request of industrial developers in 
Table 1. List of Physiological Functions Covered by Functional Food

\begin{tabular}{|c|c|}
\hline Sub-classes & Functions \\
\hline Brain and head & Memory function, cognition function, relaxation, eye health, teeth health \\
\hline Cardio- circulatory system & $\begin{array}{l}\text { Blood circulation, blood pressure control, cholesterol control, triglyceride control, body fat reducing } \\
\text { function, glycemic control }\end{array}$ \\
\hline Digestive system & Liver health, intestinal health, digestive function, calcium absorption \\
\hline Urogenital system & $\begin{array}{l}\text { Urinary track health, urination function, prostate health, sperm motility, vaginal health, andropause man } \\
\text { heath, menopause woman heath, premenstrual syndrome control }\end{array}$ \\
\hline Bone-muscle system & Joint-bone health, exercise ability or endurance, help growth of child, \\
\hline Skin & Skin health, immune reaction-medicated skin trouble control \\
\hline Immune system & Immune function, anti-fatigue function, antioxidant activity \\
\hline
\end{tabular}

Korea as well as aboard. To date, 30 of 31 functions, except for sperm motility control, have been applied by individual-authorized functional foods.

\section{Increase of approved materials for individual-authorized functional food}

The number of approved materials for individual -authorized functional foods by Korean MFDS continuously increased from 7 in 2004 to 65 in 2014. Total 313 food materials have been approved by August 2015 (Fig. 1). Recently many kinds of herbal plants have been approved as materials for individual-authorized functional foods, such as mulberry leaf extract, and extract mixtures containing Astragalus membranaceus Bunge or Gastrodia elata Blume for glycemic control, helping child growth, and memory function respectively.

\section{Individual-authorized functional materials according to physiological function}

Regarding 31 physiological functions, the most prevalent targets of 313 individual-authorized functional materials involved body fat reducing function (31 materials), skin health (31 materials), glycemic control (23 materials), memory function (22 materials), and joint-bone health (20 materials)

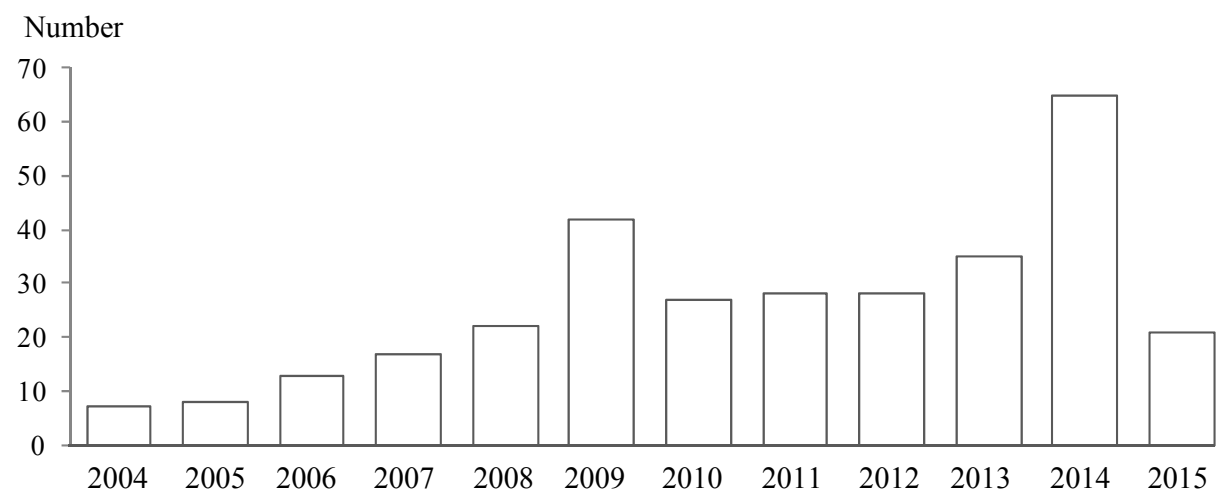

Fig. 1. Annual approval for individual-authorized functional materials. The annual number of approved material for individual-authorized functional food was shown from 2004 to 2015. 
respectively. When the approved materials since 2010 year was counted for analysis of recent pattern, anti-fatigue function (15 materials), immune reaction -medicated skin trouble control (11 materials), and premenstrual syndrome control (10 materials) were prevalent (Fig. 2).

\section{Materials recourses and functional level of individual-authorized functional foods}

When the 313 materials of individual-authorized functional foods were analyzed according to resources, Korean edible plants were most prevalent as $25.7 \%$. The next main materials were the edible plants oversea and proteins including peptides being $13.8 \%$ and $13.5 \%$ respectively.

The herbal plants were also one of main resource, such $9.3 \%$ for single herb extract and $6.4 \%$ for multiple extract with herbal plants. The $88.1 \%$ of materials were approved as functional level 2, and $10.0 \%$ for functional level 3 . The functional level 1 was only $1.6 \%$, and only one material, xylitol, has been approved as a dental caries-risk reducing function of (Fig. 3).
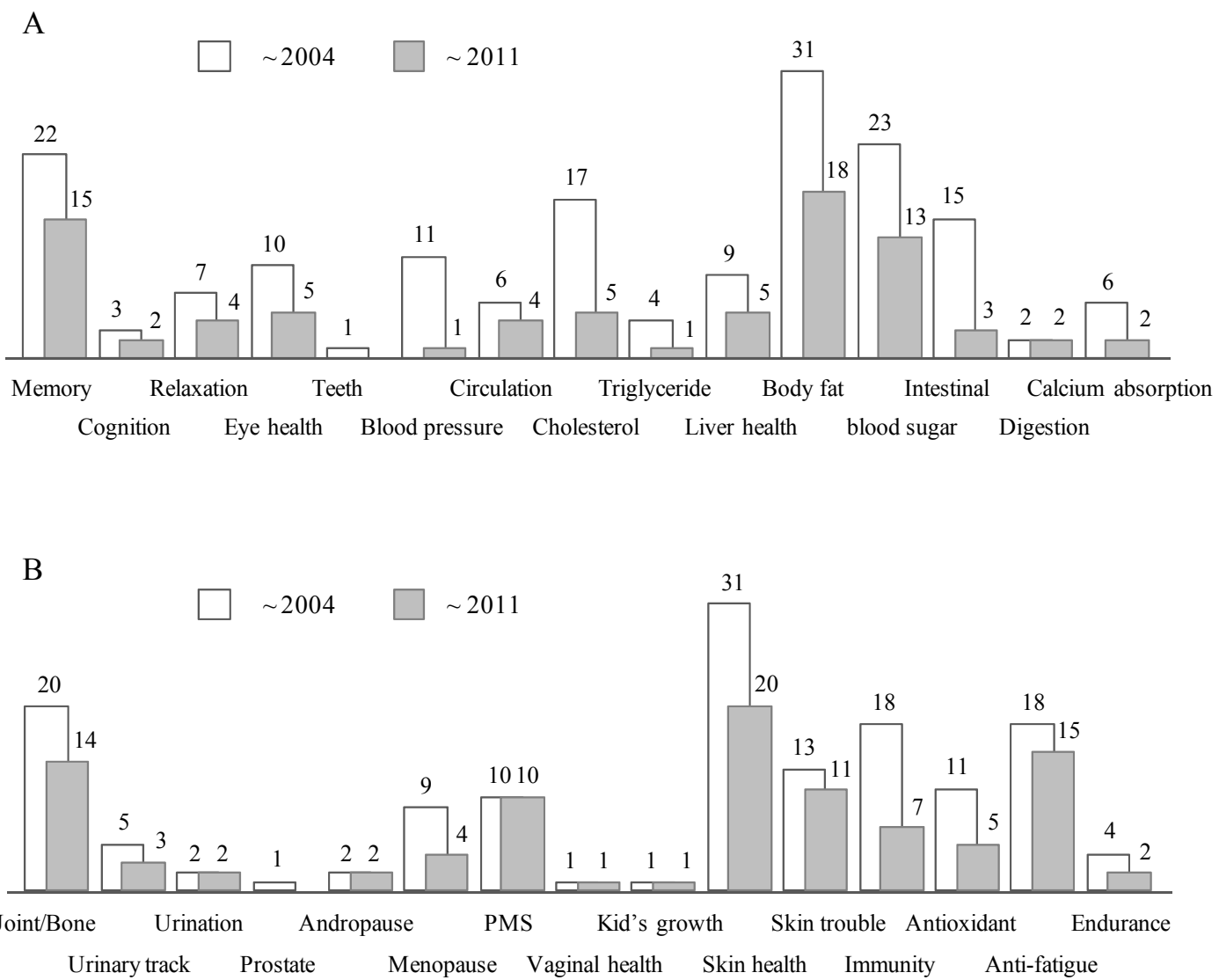

Fig. 2. Physiological functions and number of individual-authorized functional materials. The number of approved material for individual-authorized functional food was shown according to the physiological functions by 2015. 


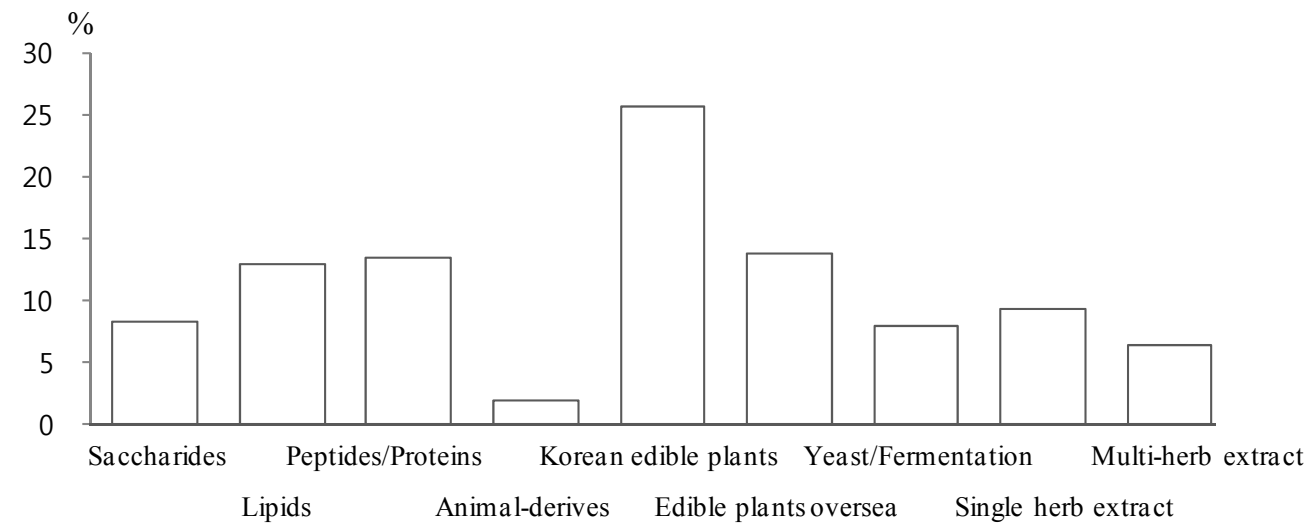

Fig. 3. Material resources of individual-authorized functional food. The potion of resource of individual-authorized functional material was shown by 2015 .

\section{Discussion}

The megatrend of current medicine is summarized as a P4 medicine, the personalized, predictive, participative, and preventive medicine ${ }^{14)}$. The global medical industry is shifting to prevention from treatment of disease, while food industry has also been paying effort on development of functional food products. In United State which has the largest functional food market, the annual growth rate of functional food industry is fastest as approximately $7 \%$ among whole industrial fields ${ }^{15}$. Regarding the role in preventive medicine, traditional Korean medicine has shown the competitiveness compared to Western medicine, while recently herbal drugs has been outclassed by the functional food. The Korean functional food market became 1.56 trillion Won in 2014 with $10 \%$ annual growth rate, which is about 55 times the total amount of herbal drug prescription in public insurance ${ }^{8}$.

In particular, this study is paying attention to rapid expansion of individual-authorized functional foods in Korea. The functional spectrum of functional foods is expending to specific aspects, for example, urination function, prostate health, sperm motility, vaginal health, andropause man heath, menopause woman heath, premenstrual syndrome control in urinary track health. This may give consumers the wrong belief of the specifically designed drug-like functional foods. Furthermore, $15.7 \%$ of individual-authorized functional foods have used the herbal materials shown in above results, which could make the consumers confused between these functional foods and herbal drugs ${ }^{16)}$. In addition, many medicinal herbs are allowed to be used as both herbal drug and especially materials of individual-authorized functional foods. For example, Angelica gigas is a typical herbal plant with various pharmaceutical actions in Koean medicine while its extract has been sold as an individual-authorized functional food with benefit of memory function ${ }^{17}$. Nevertheless, the trend of herb-derived functional food development, especially individual-authorized functional foods, will continue.

On the other hand, functional food products can be publically advertised via media such as TV home shopping or internet and consumed easily. These functional foods occasionally cause social problems, including an excess advertisement, misuse, abuse, or adverse effects ${ }^{18,19)}$. The toxicity-related happening of Cynanchum auriculatum in 2015 is a direct example 
of herb-derived functional foods in Korea. Cynanchi Wilfordii is a typical herb in Korean medicine, and then multiple herb extract containing Cynanchi Wilfordii had been approved as a an individual -authorized functional food for menopause woman heath (ID \#2010-20 by Korean MFDS) in $2010^{20)}$. Then this material had been sold up to 270 billion Won, and then turned out to show the adverse events due to being mixed with Cynanchum auriculatum. These herb-derived functional foods act as competitors of herbal drugs, and moreover these kinds of episodes frequently hurt the reputation of herbal drugs. The major portion of herbal related toxicity has been caused by not only herbal drugs prescribed by Korean doctors but by herbal food products purchased by consumer themselves ${ }^{21}$.

Although with negative aspects of functional foods, functional food development and increase of its users is stream of current times, which means Korean medicine needs the strategy for the situation. Korean medicine would learn the pattern of consumer demand from the increasing popularity of the functional foods, including standardization with scientific analysis of materials, various and convenient forms, and clinical evidence respectively. Korean medicine also has to counteract sophistically to the popularity of the functional foods. The most important strategy would be the development of convenient forms of herbal drugs, and its involvement as health-insurance covered drugs. The traditional prescription being given differently by each Korean doctor, Korean medicine cannot compete with the standardized functional products as well as western drugs, in aspect of convenient administration. The coverage of herbal drugs by national health insurance is the most impactful factor which could make Korean medicine superior to functional foods, from the point of being cost-efficient for consumer. In addition, Korean medicine should request Korean government to strongly limit the list of herbal materials which can be used for functional foods, especially individual-authorized functional food.

Korean functional food market will be growing continuously and especially the herbal-derived individual-authorized functional food will be a strong competitor. This study overviewed the current status of individual-authorized functional food in Korea, and produced essential information for developing the strategies in new environments by Korean medicine community.

\section{Acknowledgements}

This study was supported by the research program of Korean Institute Oriental Medicien (K1510) and Oriental Medicine Research and Development Project, Ministry of Health and Welfare (HI15C0112-000015), South Korea.

\section{References}

1. Shimizu T. Health claims on functional foods: The Japanese regulations and an international comparison. Nutr Research Review. 2003;16: 241-52.

2. Park SC, Oh MY, Kim HS. A Study on usage of health improving agents in Seoul \& Busan. J Korean Diet Assoc. 2005;11(4):440-8.

3. NBJ's Global Supplement \& Nutrition Industry Report 2012. Available at: URL:http://newhope360. com/sitefiles/newhope360.com/files/uploads/2013/ 04/TOC_Global_final.pdf.

4. Korean Ministry of Food and Drug Safety. Food \& Drug Statistical Yearbook in 2015. 2015;186 -88 .

5. Son CG. Progress of Functional Food Market in Korea and Strategy of Korean Medicine. J Korean Med. 2014;35(1):68-74.

6. Korean Ministry of Food and Drug Safety. Available at: URL:http://www.foodnara.go.kr/ hfoodi/main/sub.jsp?pageStr $=10$ \&pageCode $=260$ 
\&viewType $=$ list\&searchType $=$ strSubject\&keywor $\mathrm{d}=$.

7. Korean Ministry of Food and Drug Safety. Analysis Report for Annual Production of Functional Foods in 2013. 2014;1-7.

8. Health Insurance Review and Assessment Service. 2013 National Health Insurance Statistics for drug prescription. 2013:80.

9. Kwak NS, Kim JN. A Proposal for Improving the Regulatory System due to the Permission of Functional Claims for Ordinary Foods. J Welfare Forum. 2009;158:48-54.

10. Imfact, 2013 Market Report for Functional Foods and their Materials. Seoul. 2013:65-8.

11. Moon JS. Study on Strategics of Health Food Industry. Korean Health Industry Development Institute. 2004;12-3.

12. Korean Ministry of Food and Drug Safety. Available at: URL:http://www.foodnara.go.kr/ hfoodi/main/sub.jsp?pageCode=1.

13. Korean Ministry of Food and Drug Safety. Available at: URL:http://www.foodnara.go.kr/hfoodi/ industry/main/sub.jsp?pageCode=2.

14. Sobradillo P, Pozo F, Agusti A. P4 medicine: the future around the corner. Arch Bronconeumol. 2011;47(1):35-40.
15. Kim YC, Hong HD, Cho CW, Chung SK. The Trends of Functional Foods in the USA. Food Industry and Nutrition. 2015;20(1):15-7.

16. News from Digital Times. Available at: URL: $\mathrm{http} / / /$ www.dt.co.kr/contents.html?article_no $=201$ 5052202101576650001.

17. Korean Ministry of Food and Drug Safety. Available at: URL:http://m.foodnara.go.kr/hfoodi/ index.jsp?menuId=health_view\&curPage $=175 \&$ fo reignYn=N\&productSeq=203286_1\&searchId $=\& s$ earchStr $=$.

18. Ohn J, Kim JH. Intake Pattern and Needs Assessment for the Development of Web-Contents on Health Functional Foods according to Age of Adults. Korean J Community Nutr. 2012;17(1): 26-37.

19. Hwang WM, Kim MH, Yun GR, Lee GB, Go JM, Kim YH. A study on safety of functional health foods. Kor. J. Vet Serv. 2008;31(2): 239-54.

20. Korean Ministry of Food and Drug Safety. Available at: URL:http://www.foodnara.go.kr/ hfoodi/.

21. Lee WJ, Kim HW, Lee HY, Son CG. Systematic review on herb-induced liver injury in Korea. Food Chem Toxicol. 2015;84:47-54. 